\title{
O OLHAR TEÓRICO SOBRE AS FONTES DE INFORMAÇÃO E O UNIVERSO LITERÁRIO E BIOGRÁFICO DE CLARICE LISPECTOR
}

\author{
Sanielly Ianar Alves Lima ${ }^{1}$ \\ Centro Pedagógico Paulo Freire \\ sanys.22ianar@gmail.com
}

\author{
Roberia de Lourdes de Vasconcelos Andrade ${ }^{2}$ \\ UFAL \\ roberiabiblio@gmail.com
}

\begin{abstract}
Resumo
As fontes de informação são instrumentos que potencializam o conhecimento. Assim, este artigo aborda o universo teórico das fontes de informação no âmbito da Biblioteconomia e Ciência da Informação. Apresenta conceitos e as tipologias informacionais, suas características e o seu papel social, especificamente a biografia. Estabelece a correlação entre o estudo das fontes de informação e a literatura de Clarice Lispector, descrevendo o caráter literário e biográfico de sua obra. Expõe os apontamentos da crítica literária quanto à obra clariceana e as reflexões teóricas a respeito da fonte biográfica. Reconhece que a biografia, enquanto fonte de informação, dialoga com o texto literário, constituindo relações intrínsecas entre realidade e ficção.
\end{abstract}

Palavras-chave: Fontes de Informação. Biografia. Literatura. Clarice Lispector.

\section{THEORETICAL LOOK AT THE SOURCES OF INFORMATION AND THE LITERARY AND BIOGRAPHIC UNIVERSE OF CLARICE LISPECTOR}

\begin{abstract}
Information sources are instruments that enhance knowledge. Thus, this article addresses the theoretical universe of information sources within the scope of Librarianship and Information Science. It presents informational concepts and typologies, their characteristics and their social role, specifically the biography. It establishes the correlation between the study of information sources and Clarice Lispector's literature, describing the literary and biographical character of her work. It exposes the notes of the literary criticism regarding the Claricean work and the theoretical reflections regarding the biographical source. It recognizes that biography, as a source of information, dialogues with the literary text, constituting intrinsic relations between reality and fiction.
\end{abstract}

Keywords: Information sources. Biography. Literature. Clarice Lispector.

\footnotetext{
${ }^{1}$ Graduada em Biblioteconomia e Letras pela Universidade Federal de Alagoas - UFAL. Professora de Língua Portuguesa do Centro Pedagógico Paulo Freire.

${ }^{2}$ Doutora em Ciência da Informação pela Universidade Federal da Paraíba - UFPB. Professora do Instituto de Ciências, Comunicação e Artes no Curso de Biblioteconomia da Universidade Federal de Alagoas - UFAL.
} 


\section{INTRODUÇÃO}

À luz da literatura, os conceitos sobre fontes de informação são muitos e as tipologias variam de acordo com a sua composição e finalidade. Objeto de estudo da Ciência da Informação, as fontes de informação têm se diversificado nos mais variados formatos, principalmente com o surgimento da tecnologia e, sobretudo, da internet. Logo, satisfazer a necessidade dos usuários não tem sido uma tarefa simples justamente pela grande quantidade de informação que circula na sociedade e pela rapidez com que ela é propagada.

Este ensaio justifica-se pela relevante abordagem teórica sobre o universo das fontes de informação, especialmente a biografia no tocante à literatura de Clarice e busca responder a seguinte indagação: Em quais pontos a fonte biográfica está presente no texto literário de Clarice Lispector? A partir da leitura do texto clariceano é possível perceber que a linha tênue entre o ficcional e o real consolida o caráter biográfico de sua literatura.

Assim, este artigo propõe um estudo teórico acerca do universo das fontes de informação no âmbito da Ciência da Informação, apresentando os diversos conceitos, as tipologias, características e o papel social que elas exercem. Para tanto, o estudo debruça-se especificamente sobre a biografia por intermédio da literatura de Clarice Lispector.

Além disso, estabelece a correlação entre o estudo das fontes de informação e a literatura de Clarice Lispector, descrevendo o caráter literário e biográfico de sua obra; expõe os apontamentos da crítica literária quanto à obra de Clarice Lispector e as reflexões teóricas a respeito da fonte biográfica e reconhece que a biografia, enquanto fonte de informação dialoga com o texto literário, constituindo relações intrínsecas entre realidade e ficção. Logo, trata-se, pois, de uma pesquisa de caráter bibliográfico e documental, com abordagem qualitativa.

\section{FONTE DE INFORMAÇÃO E BIOGRAFIA}

Por certo, as fontes de informação são múltiplas e, de acordo com Baggio, Costa e Blattmann (2016, p. 32), “[...] a informação pontual é o elemento pelo qual o usuário inicia sua busca nas diversas fontes existentes.” Esse aspecto é pertinente, uma vez que a informação torna-se objeto central de busca e requer um sistema complexo para que ela seja alcançada. Diante disso, a disponibilização da informação em contextos e formatos diversos faz das fontes informacionais um instrumento determinante, que orienta o usuário no seu processo de busca.

No entanto, deve-se pontuar que essa grande gama de informação não surgiu recentemente. Isso porque desde a invenção da imprensa feita por Gutenberg, no século XV, 
ocorreu o que se chamou de "explosão informacional", momento em que o acesso à informação se abriu para alguns grupos sociais.

O que não se pode comparar à atualidade tendo em vista que a informação parece caminhar cada vez mais por um viés "democrático", devido à dissociação da informação enquanto fator isolado, particular, para um novo pensamento de informação popularizada que busca atingir a sociedade de maneira igualitária. Para Oliveira e Ferreira (2009, p. 70), as fontes “[...] são documentos, pessoas ou instituições que fornecem informações pertinentes a determinadas áreas."

Essa popularização informacional permitiu o surgimento de novas fontes de informação em excesso e exigiu que se determinassem categorias de classificação das fontes considerandose suas características.

Dessa forma, a partir do que assinalam Araújo e Fachin (2015), as fontes de informação são classificadas de acordo com suas tipologias em: fontes primárias; fontes secundárias e fontes terciárias, às quais Grogan (1970) denomina “documentos".

Os primários contêm novas informações, os secundários são oriundos dos primários, ou seja, são o que Grogan (1970) chama de “organizadores dos documentos primários” e, nesse sentido, são utilizados como um guia pelo leitor. Os terciários, por sua vez, são sinalizadores de localização sobre os documentos primários e/ou secundários.

Essa delimitação categórica estabelecida entre as fontes de informação confirma a noção de que elas são distintas, por essa razão, carregam características e finalidades diferentes. A categorização permite que o agrupamento dessas fontes, a partir de suas tipologias, possibilite uma combinação entre as fontes, isto é, uma inter-relação.

O diálogo entre fontes informacionais é frequente em produções biográficas, que em sua maioria se formam por meio de outras fontes de informação. Conforme afirma Cunha (2001, p. 45), a biografia é um “[...] tipo de documento ou fonte de informação que relata a vida e a atividade de alguém." Nessa perspectiva, a biografia fortalece o diálogo com outras fontes porque se apropria delas para formar sua própria composição.

As fontes de informação, por sua pluralidade, podem representar diversos aspectos, desde os sociais (conteúdos), os físicos (que correspondem ao ambiente em que se pode encontrá-las) até os organizacionais (ligados ao processo de tomada de decisão).

Essa amplitude ressalta o quão complexo é o ambiente das fontes de informação, principalmente porque não se limitam apenas à fonte em si, mas consideram-se tudo que está em volta. Deste modo, tal qual declara Carrizo Sainero (1994) citado por Morigi e Bonotto 
(2004), ao fornecerem respostas específicas nas fontes de informação é possível encontrar todos aqueles elementos que, submetidos à interpretação, podem transmitir conhecimento.

As fontes, nesse sentido, são vistas como instrumentos que potencializam o conhecimento em quaisquer esferas, isto é, são como afirma Gomes e Dumont (2015), veículos potenciais que podem possuir uma determinada informação para um determinado sujeito para satisfazer uma determinada necessidade. Isso reafirma a concepção de que elas têm uma finalidade definida e, por esse motivo, sua categorização depreende satisfazer a necessidade dos usuários de forma precisa. Dessa maneira, as tipologias das fontes não são delineadas ao acaso, tem-se um sentido nisso, pois perpassa pelo intuito de tornar real a busca do usuário pela informação que ele deseja.

Ao se inserir na categoria de fonte de informação secundária, isto é, aquela que contém informações sobre as fontes primárias, a biografia sustenta a concepção de que uma fonte não é formada isoladamente, ainda que sejam as primárias. Para ser uma fonte, é preciso reunir fatos, compor ideias, estabelecer reflexões e essas ações necessitam de pesquisa, de busca por outras fontes, como dados estatísticos, fotografias, depoimentos, entre outros.

$\mathrm{Na}$ biografia, essa reunião de fontes é peculiar, porque além de acrescentar maior significado à sua produção, proporciona também o entendimento mais relevante das fontes originárias (primárias) que lhe serviram de base para a sua composição.

Nisso, é estabelecida a seguinte percepção: de que as fontes secundárias, como a biografia, dependem de outras fontes para existir como uma natureza que se correlaciona com outras naturezas, às quais possuem características distintas, mas que se complementam e propiciam o sentido mais amplo de si e das fontes que foram usadas.

Dessa maneira, vale assinalar que a composição da biografia, como fonte de informação, vai além do processo de escrita de dados sobre alguém. É necessária a investigação simultânea, a busca incessante por fontes precisas, que assegurem maior exatidão.

Para se produzir uma biografia, é preciso muito mais do que pontuar os principais fatos vividos por quem está sendo biografado. Faz-se necessário uma busca aprofundada de informações que certifiquem com clareza o texto biográfico.

De acordo com Campello e Caldeira (2008, p. 44), a biografia, na qualidade de gênero histórico-literário, é entendida "[...] como um tipo de obra dedicado à vida de uma pessoa especial, difere da simples informação biográfica sobre um indivíduo, em termos de conteúdo, finalidade e estilo." Isso fortalece a noção de que a biografia necessita de elementos que complementem sua construção. 
Nessa perspectiva, as biografias sobre Clarice Lispector têm essa arquitetura de forma visível, uma vez que a presença de outras tipologias de fontes informacionais está presente ao longo dos textos e possibilitam construir reflexões. Todavia, é preciso salientar que essas tipologias de fontes informacionais não estão presentes em toda as biografias da autora, e não são as únicas. O intuito, na realidade, é a afirmação de que a biografia, como qualquer fonte de informação, não é um elemento isolado, mas necessita de outras fontes para sua composição.

Diante disso, a diversidade das fontes de informação que compõem a produção biográfica de Clarice Lispector consolida a tese de que a biografia, enquanto fonte, não é elaborada de maneira separada. Ao contrário disso, ela é fruto de uma pesquisa minuciosa de documentos distintos que colaboram para a sua formação. $\mathrm{E}$ as origens distintas das fontes que cedem esses documentos determinam a riqueza de conteúdo que integram as biografias da autora.

Essa pluralidade das fontes de informação inserida em algumas obras biográficas sobre Clarice provoca o dilema que paira a respeito da "Biografia". Como é possível classificá-la, se no decorrer de seu percurso caminha para o entrave entre a História e a Literatura? Como determinar se sua composição é feita de traços reais ou ficcionais? Essas são algumas das indagações que permeiam a biografia, quer seja fonte, quer seja gênero textual, as quais serão discutidas na subseção a seguir.

\subsection{A fonte de informação biográfica: realidade ou ficção? ciência ou arte?}

O dilema dicotômico da biografia é percebido até mesmo em sua origem enquanto vocábulo. Derivada de dois termos gregos: bios (vida) e graphein (escrever), a biografia sinaliza segundo Vianna e Marques Júnior (2008, p. 43), “[...] a ideia de narrativa, descrição, registro ou história de vida de uma pessoa."

Estabelecer uma categoria classificatória para a biografia não é um exercício fácil, principalmente quando se considera seu aspecto antigo (quanto à sua existência). Logo, a dificuldade em estabelecer uma definição para a biografia é justificada pelas distintas características apontadas por Borges (2011): "gênero compósito", "híbrido", "controverso", "problemático", "confuso", "duvidoso".

O que se pode determinar é que, dependendo de sua finalidade, a biografia pode ser identificada ora como realidade ora como ficção e, nesse contexto, predetermina-se o conflito entre Ciência e Arte. Silva (2009, p. 152) diz que: “[...]mais discutida do que as origens da heteronomia no poeta português é a temática do biografismo, um gênero literário e 
historiográfico no qual o hibridismo origina paixões, censuras e tensões." Ou seja, o aspecto real e/ou ficcional da biografia perpassa pela hibridez do texto produzida por aquele que escreve: o biógrafo e o que lê: o leitor.

No viés da Ciência, a biografia é vista como fonte histórica, ou seja, pertencente à História. Em contrapartida, se vista pelo viés da Arte, a biografia apresenta-se como gênero textual narrativo e, portanto, inserida no campo da Literatura, ou seja, ficção.

Isso justifica a tensão que Dosse (2009) sinaliza sobre a biografia, a qual é provocada pelo desejo de dizer a verdade e construir uma narração, sendo, portanto, ficção. Essa tensão circunscreve o que o autor chama de "ponto médio" entre ficção e realidade histórica.

Assim, supõe-se que essa fonte insere-se numa linha tênue entre o real e o ficcional sustenta a ideia de que a biografia em sua natureza não é homogênea, isto é, ela é formada a partir da mistura dessas duas vertentes que, embora distintas, dialogam entre si e conferem à biografia um valor, quer seja histórico/científico, quer seja artístico/literário. Para Dosse (2009), o gênero biográfico apresenta duas identidades: a literária e a científica acentuando-se, portanto, o seu aspecto intermediário, mesclado e híbrido.

Segundo Borges et al. (2011, p. 214): “[...] a própria vida do biografado fornecerá pistas para outras fontes, como sua produção no campo da arte, da indústria, da política, da ciência etc." Portanto, a hibridização presente na biografia, não é voluntária, ela é condicionada por vezes pela relação entre biógrafo e biografado.

Logo, mediante a caracterização desse valor, constata-se, conforme afirma Vianna e Marques Júnior (2008), que a busca pela informação biográfica pode referir-se tanto a uma simples questão (datas, formação, filiação...) quanto a fatos mais complexos (atuações em atividades, período histórico).

Dessa forma, a biografia possibilita a ampliação da busca pelo que se procura, uma vez que não se limita apenas a dados pessoais de quem está sendo biografado, mas também pode auxiliar no encontro de informações que estão para além do aspecto pessoal desse indivíduo.

As fontes biográficas, segundo Martin Vega (1994 apud VIANNA; MARQUES JÚNIOR, 2008, p. 44) são "[...] documentos [...] que fornecem dados fundamentais (do tipo quem é, onde nasceu, o que fez, onde se formou, onde vive sobre a vida de pessoas pertencentes ao passado, ou vivas no presente [...]" Sobretudo, a biografia, quando fonte de informação, pode ser vista de acordo com Vianna e Marques Júnior (2008, p. 43), como “[...] recurso para obtenção de informações as mais diversas possíveis sobre um período histórico, uma nação, uma instituição.” Nesse sentido, a biografia propicia ao biógrafo a construção de um texto que advém de fontes diversas, como uma coletânea. 
A biografia, talvez por sua origem, ou seu trajeto percorrido ao longo da história e por seu aspecto híbrido e controverso, assegura a representação de gênero intrigante. No entanto, ao se observar que desde a sua origem até os dias atuais a biografia tem se reinventado e revela que, mais do que misterioso, trata-se de um gênero inspirador.

Sua pluralidade é notável ao se considerar que diversos tipos de textos podem ser vistos como biografias, tal qual pontua Borges et al. (2011, p. 204), "[...] desde um verbete em dicionários de figuras políticas, literárias, até relatos em filmes, documentários, programas de televisão, etc."

Por seu caráter antagônico, a biografia, durante muito tempo, opôs-se à História por diversas razões, mas a principal delas é que a biografia ora foi vista como ciência, ora como literatura. E esse é um sério motivo para trazê-la à tona e levantar reflexões a seu respeito. A História, por sua vez, apropriou-se da biografia para contar fatos do seu próprio caminho e, nesse caso, sempre se apresentou como ciência.

A partir desse antagonismo afirma-se o pensamento de Avelar (2010) de que a biografia provoca um polêmico questionamento imposto a um gênero que segundo o autor é "verdadeiramente literário", mas possui uma dimensão "puramente científica".

Essa distinção acaba desencadeando, segundo Avelar (2010, p. 161): “[...] a mescla, o hibridismo, e expressa, assim, tanto as tensões como as convivências existentes entre literatura e Ciências Humanas."

Desse modo, a biografia foi reconhecida, conforme afirma Del Priore (2009, p. 7), “[...] como uma das primeiras formas de história." Essa afirmação estabelece de fato o clássico papel da biografia que consiste em narrar fatos e acontecimentos sobre a vida de uma pessoa; e, portanto, também é história. A biografia, conforme descreve Del Priore (2009), sofreu mudanças ao longo dos tempos. O Renascimento Cultural ocorrido no século XIV evocou a exaltação ao indivíduo e deixou para trás o teocentrismo que imperou durante a Idade Média. Del Priore (2009) pontua ainda que o homem se tornou o centro. Essa visão antropocêntrica foi determinante para o desenvolvimento da biografia.

As bases que sustentavam o Movimento Renascentista, candidatando o indivíduo como centro do mundo, acresceram a quantidade de produções biográficas. O individualismo, que também foi foco nos séculos posteriores, concretizou a formalização do conceito de biografia tal qual assinala Del Priore (2009, p. 8), como “[...] palavra que dicionarizada em 1721, designava um gênero que tinha por objeto a vida dos indivíduos."

No século XIX, a biografia confabulou para a construção do ideal de "nação" no intuito de imortalizar heróis, reis, personalidades de grande relevância para a história da humanidade. 
Entretanto, esse olhar para os grandes nomes da história social limitou a produção biográfica e esse fator culminou para o surgimento de uma "nova" concepção acerca da biografia.

A reconstrução do gênero parte, agora, da ideia de contar a história não mais dos grandes nomes, mas sim a história de uma época por meio de uma pessoa que faça parte desse contexto, que de algum modo tenha contribuído para este momento.

Isso reforça o pensamento de Del Priore (2009) de que, ao deixar para trás o olhar isolado para o indivíduo e enxergá-lo como parte do coletivo, biografia provocou a desmistificação do herói e passou a vê-lo como pessoa comum.

Nesse contexto, a biografia abandona a prática da "hagiografia", que conforme Del Priore (2009) concentra-se na revelação de vidas exemplares como as dos santos e passa a dar relevância àqueles que não são tão célebres, ou seja, abrem-se nos textos biográficos os espaços para o indivíduo comum em detrimento ao grandioso.

Desta maneira, a biografia deixa para trás o caráter tradicional, superficial, anedótico e cronológico descrito por Jacques Le Goff (1990) e sucede agora como uma nova maneira de contar uma história, isto é, não mais pelo olhar direcionado a uma só pessoa, mas por meio dessa mesma pessoa, visando enxergar a história de tantas outras maneiras.

De acordo com Le Goff (1989, apud BORGES et al., 2011, p. 209), “[...] a biografia é um complemento indispensável da análise das estruturas sociais e dos comportamentos coletivos." Essa colocação sustenta a tese de que no indivíduo reside a chance de compreensão das questões sociais e das relações coletivas.

Logo, a biografia de um indivíduo reflete a vida de outros, ou seja, pode conter várias outras como declara Del Priore (2009). Todavia, para se revelar dessa forma, a biografia então desfaz a separação que há entre indivíduo e sociedade, e, nesse ponto, considera o contexto social como sendo um elemento capaz de interferir em sua produção. Nesse sentido, a observação feita por Del Priore (2009) de que o indivíduo não existe só, de que sua existência decorre de relações sociais diversificadas, tem sua pertinência porque reforça a convergência que há entre indivíduo e realidade.

Essa intrínseca relação com o contexto social permitiu que novos conceitos e novas formas de ver a biografia como um gênero dialógico surgisse anos mais tarde. Silva (2009), por exemplo, sustenta a ideia de que a construção biográfica perpassa pelo diálogo com as diferentes formas que servem para simbolizar o tempo, o indivíduo e as sociedades.

Em meio ao seu aspecto "confuso", debruçar-se sobre esse gênero parece ser bastante atrativo e relevante, uma vez que a biografia perde o seu elitismo, porém ganha em popularidade 
ao abrir espaços para o homem comum como seu objeto de estudo e, além disso, amplia os seus horizontes; o individual, que ainda é muito presente para o coletivo que ganha seus espaços.

A biografia cede lugar para a coletividade pelo olhar de uma só pessoa como uma espécie de espelho e esse fato lhe propõe elaborar novas formas de se contar não apenas as histórias dos grandes homens, mas também considera significativa a possibilidade de narrar a história dos homens habituais e enaltecer ainda mais o estudo desse gênero, que é de suma importância para a construção de um povo, de uma sociedade.

Essa perspectiva de enxergar por intermédio do individual, o coletivo permitiu o processo de queda e ascensão do gênero biográfico, justificado pela capacidade de retratar a totalidade social por meio de uma trajetória de vida pessoal. A essas duas fases que dividem o caminho da biografia colocam-se a Ciência e a Literatura como elementos opostos que delimitaram ao longo da história os fracassos e as conquistas da biografia.

Isso recai sobre o que Motta (2000) chama de "desqualificação" do gênero biográfico. Para o autor, a associação da biografia à imprecisão e à subjetividade estabelece a fronteira entre a literatura e a história. Logo, evidencia-se a "promiscuidade" biográfica.

Ainda de acordo com Motta (2000), essa oposição entre Ciência e Literatura provoca rompimentos no percurso da biografia, sobretudo pelo enaltecimento do indivíduo em detrimento do coletivo em que é possível construir uma via de acesso ao conhecimento social.

As biografias e as autobiografias consolidam as distâncias científico-literárias. Ambas permitiram a construção da narrativa contando histórias de pessoas sociais. Para Motta (2000, p. 5), a biografia “[...] vinculou-se a certo exercício apologético dos heróis nacionais, sendo considerado por isso mesmo um dos pilares do complexo processo de construção das nações."

Outra razão determinante para o distanciamento literário e científico da biografia está, conforme pontua Motta (2000, p. 5), “[...] com a adoção de métodos documentais mais rigorosos, [...] ao mesmo tempo comprometido com a liberdade ficcional e descomprometido com o rigor de investigação e a verdade histórica."

Mas, ainda que os distanciamentos sejam comprovados, não se podem anular os diálogos existentes entre a biografia, a literatura e as ciências. Esse contato é fundamental para justificar as ações humanas e as mudanças no tempo e no espaço.

Em relação à literatura, por exemplo, a aproximação acontece na possibilidade de formação de vários "eus" construídos pelo escritor. Logo, a literatura: "[...] trabalha com a multiplicidade de pessoas que cada um é, interessa-se por qualquer homem (o chamado homem comum) e não apenas pelo 'grande personagem'.” (BORGES et al., 2011, p. 214). 
Portanto, o que se cabe pontuar é que a relação dialética entre Biografia e Literatura não pode ser excluída, pois permite o exercício da leitura de um indivíduo que ora é real porque se insere num determinado contexto social, ora é ficcional à medida que se insere numa estrutura narrativa composta de elementos de caráter literário e, quando unidas, as estruturas anunciam informações sobre a pessoa (que está sendo biografada), a época e o contexto social.

\section{O VIÉS BIOGRÁFICO E AS NOVAS DESCOBERTAS ACERCA DA LITERATURA DE CLARICE LISPECTOR}

Seja como leitura literária, seja como pesquisa biográfica, Clarice Lispector é inspiradora de qualquer forma. Sua vasta literatura justifica essa afirmativa ao narrar histórias do cotidiano por meio de personagens comuns, mas que ao mesmo tempo consegue romper com a trajetória linear das narrativas construindo uma escrita singular e intimista.

As biografias produzidas ao seu respeito também carregam a singularidade e o intimismo de seu fazer literário porque se apropriam destas características para sua própria composição, embora isso não seja um ponto comum entre toda as biografias.

Logo, o que mais chama a atenção é a maneira como sua escrita literária coopera para a construção das biografias a seu respeito, ou seja, sua própria história também se torna arte e fonte pelo olhar do biógrafo. Talvez pelo próprio desejo de Clarice, sua literatura prova que também é biografia, já que preenche boa parte de seu espaço e se torna elemento do próprio percurso criativo do biógrafo.

Nascida em Tchetchélnik, em 1920, na Ucrânia, Clarice chega ao Brasil com um ano e três meses de idade, em Maceió (AL), onde permanece pouco tempo e vive a infância e parte da juventude no Recife (PE). Inicia sua carreira como escritora ainda muito jovem produzindo contos, que serão publicados posteriormente.

Formou-se em Direito no Rio de Janeiro e ainda na cidade carioca, iniciou a carreira como jornalista publicando crônicas nos jornais. Em 1943, lançou seu primeiro romance: Perto do Coração Selvagem, inserindo-se definitivamente no meio literário brasileiro.

Essas informações demonstram a "fonte" que é Clarice Lispector; ela de certo vai muito além de um novo rosto feminino no cenário literário; sua forma de escrever "tão diferente" impressionou a crítica literária e deslumbrou muitos leitores. O crítico literário brasileiro, 
Antonio Candido (2001), descreve Clarice como uma aventureira, que cria um novo ritmo de ficção onde a linguagem é o ponto de investigação e interpretação do mundo.

Clarice é fonte afluente, quer no conto ou no romance, sua narrativa é feita e refeita a seu modo, desordenando regras da linguagem e enaltecendo um estilo único, particular. É mística e espontânea, não desrespeita a estrutura do seu texto, antes, porém, o reveste de uma linguagem plural que perpassa a superfície textual e passeia pelo íntimo das suas personagens, construindo reflexões acerca do comportamento humano.

O também crítico Sérgio Milliet sublinha a escrita de Clarice Lispector como sendo sóbria e penetrante e acresce ainda que, em Clarice: “A linguagem envereda por inesperados atalhos, atinge o poético, usa soluções inéditas, sem cair no hermetismo ou nos modismos modernistas.” (MILLIET, 1945, apud SÁ, 1979, p. 24).

A riqueza da fonte clariceana é notada na pluralidade de seus escritos. Por meio de personagens e cenários corriqueiros, Clarice investiga o interior humano, com consciência de tudo que faz, expõe os desejos, as angústias, os medos humanos, sejam por meio de bichos, sejam por meio de objetos ou de espaços.

Essa investigação acontece de maneiras distintas e em diferentes aspectos. Transgressora em seu modo de ser, a "fonte" Clarice utiliza a linguagem para explorar a sua própria realidade. A partir de suas personagens, reafirma seu caráter inovador que desnuda a "coisa" humana desmistificando conceitos preestabelecidos.

Diante disso, Candido (1985, p. 250) destaca que: “[...] Clarice mostrava que a realidade social ou pessoal (que fornece o tema), e o instrumento verbal (que institui a linguagem) se justificam $[\ldots]$ ", produzindo o que o autor chama de "[...] uma realidade própria, com sua inteligibilidade específica." (CANDIDO, 1985, p. 250).

Por meio da reflexão de Candido (1985), percebe-se que a literatura de Clarice, como fonte de informação que é, projeta o texto como elemento inesgotável, isto é, a fronteira existente entre o real e o literário é perene.

Clarice também é fonte incomum e isso é notável desde sua origem até a chegada ao Brasil. A perda de sua mãe ainda na infância, estabelecendo a quebra das tradições judaicas da qual era seguidora; a escolha pela carreira de direito sem pretensões nenhuma de exercer a profissão; todas essas razões já são motivos mais que suficientes para considerá-la conteúdo surpreendente.

Ao lançar seu primeiro romance Perto do coração selvagem, em 1943, em plena juventude, impacta a crítica literária com sua escrita de caráter estranho e inovador e por fim o fato de ter se casado com um diplomata, no qual o seu papel era o de acompanhá-lo a inúmeras 
viagens, tudo já demonstra que sua existência de certo nunca foi pacata; Clarice esteve sempre à beira do imprevisível.

A "fonte" Clarice Lispector se multiplica em conteúdo e forma, as biografias a seu respeito são uma demonstração dessa diversidade de informações. Há a respeito de Clarice muito mais do que dados pessoais, há o que se pode entender de "reencontro" com o próprio fazer literário da escritora, uma vez que é nítida a presença de traços de sua escritura nos textos produzidos por biógrafos que viram em sua figura aspectos que a tornam singular.

A Clarice "escritora", que produz contos e romances, está lá nas biografias, nas entrelinhas do texto, por intermédio de suas fotografias; ela é uma fonte que se refaz a partir de tantas outras. Sua postura ficcional dividida entre a conformidade e a angústia interior está presente no seu comportamento como mãe, esposa, mulher e cidadã. Clarice revela-se e expõe seus conflitos a partir de suas personagens.

Nesse sentido, é possível compreender que sua criação literária é uma forma de escrever sobre si mesmo tal qual pontua Massaud Moisés (1989) de que a ficção de Clarice Lispector divide o homem e lhe impõe um estado de permanente angústia.

Para tanto, Clarice se desdobra nas personagens que cria para falar de seu próprio eu, tal qual faz nas cartas que envia, nas entrevistas que concede e nas fotografias registradas. Essas e tantas outras fontes são mais uma maneira da Clarice "real e ficcional" se fundir e todas essas informações estão contidas em suas biografias.

Lima e Moraes (1999) certificam-se dessa fusão entre autora e obra ao perceberem que isso faz parte do processo da escrita clariceana e sustentam a tese que quando Clarice escreve, ela é "mestre" e/ou "refém" de sua própria escritura. "É no outro que ela se afirma e se reconhece enquanto Ser.” (LIMA; MORAES, 1999, p. 195).

A partir da compreensão dos autores, entende-se que a fusão entre ficção e realidade, na literatura clariceana, é fruto de uma intencionalidade desejada, especialmente no que tange à subjetividade, cuja percepção se dá tanto em sua narrativa quanto nas biografias.

É pelo caráter subjetivo presente no gênero biográfico e literário que Clarice tece sua arte e sua própria história. Ou seja, não é obra do acaso, mas sim de uma racionalidade precisa e aguçada pela própria Clarice que é sustentada pelos biógrafos, os quais compreendem que para se falar sobre a autora é preciso traçar uma linha tênue entre o ficcional e o real, como se ambos fossem um só.

\subsection{O biografismo e o ficcional na literatura de Clarice Lispector}


De fato, a literatura de Clarice Lispector é instigante e paradoxal. Estudiosos de sua obra não chegam a uma opinião comum sobre a sua criação literária. Para a filósofa francesa Hélene Cixous, a literatura de Clarice é filosofia; para o romancista brasileiro Otto Lara Resende é bruxaria; para o poeta Arthur Rimbaud, feitiçaria e até telepatia, como definiu a escritora canadense, Claire Varin. Essas possibilidades de definição indicam o quanto a literatura de Clarice Lispector é intrigante e plural.

Para Castello (2011, p. 13), a literatura de Clarice Lispector “[...] tem, em consequência, a forma de uma roda que, em uma translação enlouquecida, e com um grande oco em seu centro, fulmina e mata - pobre ser dormente - o leitor." Entretanto, é possível estabelecer uma opinião coerente: a vida de Clarice é vista pelo olhar de suas personagens numa espécie de cruzamento entre o real e o imaginário.

Essa opinião aproxima-se do pensamento de Castello (2011) que reconhece a avareza dos conteúdos nos romances de Clarice. Mas essa avareza não proíbe a realização de uma literatura reflexiva. É isso que propõe Clarice: uma reflexão do outro, do social, e de si mesma. É o que Castello (2011) destaca como uma “[...] escrita que navega sem rumo, como um cometa desgovernado a literatura de Clarice Lispector é, antes de tudo, uma escrita da ignorância e do fracasso."

Essa escrita, à deriva, é vista em "A hora da Estrela" (1977). A personagem Macabéa, diante de suas misérias, permite à própria Clarice a apropriação de sua figura para contar sua trajetória nordestina. Como pontua Zinani (2017, p. 23), "a atuação de Clarice na área das letras transitou entre ficção e não ficção.” Isso justifica os percursos de Clarice e Macabéa, que ora são reais, ora ficcionais.

A literatura de Clarice é, a um só tempo, biografia e ficção, porque, mediante o seu ofício, Clarice Lispector se mostra biógrafa e escritora, tal qual assinala Borges et al. (2011, p. 218) “[...] as melhores biografias são aquelas em que o autor não só não se esconde, mas constrói a narração de certa forma acompanhando seu percurso de pesquisa."

Clarice também faz essa construção narrativa de biógrafa e ficcionista em "Perto do coração selvagem" (1943), seu primeiro romance, em que a personagem Joana, diante da morte de sua mãe e de seu pai, faz da solidão sua companheira. A escritora oferece à Joana seu próprio destino solitário (a menina que ainda muito cedo perde sua mãe e mais tarde seu pai e vive amparada por suas irmãs). Logo, Castello (2011, p.16) assinala que em Perto do coração selvagem (1943): “Clarice nos faz ver que o esforço para narrar uma vida não é um luxo, ou uma vaidade, mas a única maneira de realmente existir." Ou seja, é por meio da própria escrita que Clarice habita. 
Silva (2009, p.153) aponta que o processo de construção biográfica “[...] exige o diálogo com as diferentes formas de controle simbólico do tempo e da individualização nas sociedades humanas [...]." Isso reitera o biografismo na literatura de Clarice Lispector visto na contextualização social de suas narrativas e na criação de suas personagens, o diálogo entre a autora e sua criação literária parecem percorrer o mesmo caminho.

De acordo com Del Priore (2009, p.11), a biografia consiste numa "[...] narrativa de acontecimentos encadeados e uma intriga codificada por fatos reais, interpretados." Assim, percebe-se esse encadeamento na literatura de Clarice Lispector, quando se cruzam a vida real da autora e a imaginária.

Deste modo, a narrativa biográfica, como pontua Borges (2009), está imbricada nas subjetividades e, por essa razão, permite ao biógrafo a possibilidade de falar de si mesmo enquanto fala do outro.

Esse entrecruzamento entre realidade e ficção existente na literatura de Clarice Lispector acontece pelo aspecto subjetivo que entremeia esses dois pontos. Born (2001, p. 245) salienta o valor da subjetividade quando diz que: “[...] a biografia trata da interpretação subjetiva da trajetória da própria vida de uma pessoa.” Essa afirmação sustenta o laço de intersecção entre a vida e a obra de Clarice que, por meio de suas personagens, discorre sobre fatos e trajetórias de sua própria história.

Em Uma aprendizagem ou o livro dos prazeres (1969), a personagem Loreley (Lóri) percorre o deslocamento da cidade de Campos para o Rio de Janeiro como fez a própria Clarice ao sair de Recife para o mesmo Rio de Janeiro. Deste modo, depreende-se que o biográfico e o ficcional são construídos paralelamente por Clarice quando, de acordo com Born (2001), apresentam interpretações subjetivas de experiências individuais.

Conforme reitera Tadié (1970) apud Schmidt (2003, p. 60), "Em todos os gêneros literários, para além de toda as escolas, e mesmo nas reações as mais anti-românticas na aparência, a subjetividade se afirma como em nenhuma outra época." Portanto, é pelo aspecto subjetivo que se estabelece o vínculo de aproximação entre a literatura e a biografia de Clarice Lispector.

Como pontua Romani (2016, p. 14), o texto biográfico é: “[...] carregado de uma narratividade que torna o estilo da escrita muito mais literário do que, por exemplo, um trabalho de história quantitativa.” Portanto, a biografia obedece ao seu caráter narrativo de contar uma história, solidificando o estilo literário. 
Nesse sentido, o historiador, que também é um literato de acordo com Romani (2016) necessita do domínio narrativo para estabelecer o elo entre história e arte, entre história e literatura. Nisso compreende o ponto de intersecção.

E a subjetividade perene existente na obra de Clarice Lispector admite a aproximação com a biografia, cujo subjetivo também é notável pelo olhar do biógrafo. Encerra-se então a ideia de que é inalcançável o diálogo entre realidade e ficção.

Tal qual descreve Solano (2010, p. 9), a subjetividade ocorre na biografia quando: “[...] diante da variedade e formas de compor uma biografia, o escritor deve inventar sua própria forma de dizer sobre o outro. Sem se esquecer, é claro, que, ao falar sobre outra pessoa, está fazendo referência direta a si mesmo."

Em Clarice, isso se justifica por meio da criação de suas personagens e do contexto social em que elas são inseridas. As personagens são na realidade "Clarice" de várias maneiras e o contexto traduz os mesmos espaços percorridos pela escritora, como um processo mimético, isto é, representativo de si mesma. Clarice impõe, por fim, o que afirma Barthes ${ }^{3}$, ao dizer que a escrita se faz quando o centro do processo da palavra se dá atingindo-se a si próprio.

Tratando-se das biografias sobre Clarice Lispector, é pela subjetividade de cada biógrafo que se depreende a figura da escritora, mediante o escape da rotina biográfica em apresentar fatos de vida apenas.

Do mesmo modo Clarice faz em suas narrativas, foge pelas ações e os espaços narrativos, por meio de suas personagens, que ela mesma constrói e que são: femininas (a maioria delas), donas de casa, mães, mas carregam em si a trajetória de vida da própria Clarice.

Dessa forma, a literatura de Clarice Lispector é biografia e ficção, porque se faz do percurso real da autora para tecer o percurso de suas personagens em uníssono. Numa demonstração de que o diálogo entre literatura e biografia é possível e o qual, Clarice faz esse exercício com propriedade ao usar como elemento mediador a subjetividade.

\section{CONSIDERAÇÕES FINAIS}

As reflexões feitas neste artigo garantem: o universo das fontes de informação é diversificado e resulta em conceitos e tipologias distintas a depender de sua finalidade. Mas é

\footnotetext{
${ }^{3}$ Clarisse Fukelman, no capítulo de apresentação do livro A hora da estrela (23 a edição), cita o pensamento reflexivo do escritor Roland Barthes para justificar a forma como Clarice Lispector constrói a tessitura do texto literário.
} 
preciso reafirmar que a amplitude das fontes informacionais não é por acaso; ela decorre da evolução do tempo, da tecnologia e, sobretudo, do surgimento da internet.

Os diferentes formatos e suportes usados para disseminar informação têm possibilitado a busca incessante e o fácil acesso à informação. Logo é preciso estabelecer critérios para classificar as novas informações. Nesse contexto, configura-se utilizar as tipologias informacionais descritas como fontes primárias, secundárias e terciárias. Essa delimitação categórica, por sua vez, é estimulada pelas características distintas e pelo objetivo de cada tipo de fonte.

No tocante à biografia, que é objeto de análise deste estudo, é oportuno destacar a reunião das inúmeras fontes que faz parte de sua composição. Por ser um tipo de fonte que no seu aspecto tradicional narra a vida de uma pessoa, a biografia põe em xeque a inter-relação entre fontes diferentes.

Assim, a biografia caminha no entremeio da história e da literatura para efetuar seu objetivo, que é o de contar a vida de alguém, mas não limita apenas a isso, uma vez que permite a reunião de outras fontes de informação provando que não se forma isoladamente.

Ao se identificar a proximidade entre biografia, história e literatura, é possível constatar os dilemas vividos pela biografia: o seu relato ora é real, ora ficcional, sua natureza ora provém da ciência ora da arte e a sua dupla personalidade produz um aspecto complexo, híbrido, duvidoso, que só pode ser revelado a partir de sua finalidade.

Nesse sentido, a biografia funciona como um recurso informacional de dados particulares de uma pessoa e de momentos históricos de um povo ou sociedade e nisso reside sua heterogeneidade.

É como se apresenta a figura de Clarice Lispector nas biografias que falam a seu respeito. Clarice é simultaneamente uma pessoa comum inserida num determinado contexto histórico e social, e um elemento ficcional e o biógrafo é uma espécie de narrador.

Clarice Lispector carrega em si e em sua literatura uma natureza biográfica. As narrativas esboçam a criação de personagens que são espelhos de si mesma e isso não ocorre aleatoriamente. Clarice provoca o encontro entre a realidade (a sua trajetória de vida) e a ficção (a trajetória de personagens que se parecem com ela). Joana, Lóri, Ana, Macabéa são algumas das "Clarices", pois vivem experiências semelhantes que as aproximam.

Deste modo, a biografia, enquanto fonte de informação, pode se apropriar de outras fontes para tecer o seu conteúdo e não necessariamente precisa se limitar à natureza tradicional da biografia, que é o relato da vida e da obra de uma pessoa. A biografia pode provocar diferentes diálogos com outras áreas, como a literatura e a história. 


\section{REFERÊNCIAS}

ARAÚJO, Nelma Camêlo de; FACHIN, Juliana. Evolução das fontes de informação. Biblos: Revista do Instituto de Ciências Humanas e da Informação, v. 29, n. 1, p. 81-96. 2015.

Disponível em: https://periodicos.furg.br/biblos/article/view/5463. Acesso em: 13 abr. 2020.

AVELAR, Alexandre de Sá. A biografia como escrita da História: possibilidades, limites e tensões. Dimensões, v.24, p.157-172. 2010. Disponível em:

http://periodicos.ufes.br/dimensoes/article/view/2528. Acesso em: 13 abr. 2020.

BAGGIO, Cláudia Carmem; COSTA, Heloísa; BLATTMANN, Úrsula. Seleção de tipos de fontes de informação. Perspectivas em Gestão \& Conhecimento, v. 6, n. 2, p. 32-47. 2016. Disponível em: https://www.brapci.inf.br/index.php/res/v/50946. Acesso em: 14 abr. 2020.

BORGES, Vavy Pacheco et al. Grandezas e misérias da biografia. In: PINSKY, Carla Bassanezi (org.). Fontes históricas. 3. ed. São Paulo: Contexto, 2011. Cap. 6, p.203-235.

BORGES, Vavy Pacheco. O "eu" e o "outro" na relação biográfica: algumas reflexões. In: NAXARA, Márcia; MARSON, Izabel; BREPOHL, Marion (org.). Figurações do outro. Uberlândia: EDUFU, 2009. p. 225-238,

BORN, Claudia. Gênero, trajetória de vida e biografia: desafios metodológicos e resultados empíricos. Sociologias, Porto Alegre, v. 3, n. 5, p. 240-265, jan./jun. 2001. Disponível em: https://seer.ufrgs.br/sociologias/article/viewFile/5736/3326. Acesso em: 13 abril. 2020.

CAMPELLO, Bernadete Santos; CENDÓN, Beatriz. Valadares; KREMER, Jeannette. Marguerite (org.). Fontes de informação para pesquisadores e profissionais. Belo Horizonte: Editora UFMG, 2000.

CAMPELLO, Bernadete Santos. CALDEIRA, Paulo da Terra. (org.). Introdução às fontes de informação. 2. ed. Belo Horizonte: Autêntica Editora, 2008.

CANDIDO, Antonio. Literatura e sociedade: estudos de teoria e história literária. 7. ed. Companhia Editora Nacional: São Paulo, 1985.

CANDIDO, Antonio. Perto do coração selvagem. In: NESTROVSKI, Nestor (org.). Figuras do Brasil: 80 autores em 80 anos de Folha. São Paulo: Publifolha, 2001. p. 74-78.

Disponível em: https://www1.folha.uol.com.br/fsp/ilustrad/fq0112200109.html. Acesso em: 13 abr. 2020.

CASTELlO, José (org.). Clarice na cabeceira: romances. Rio de Janeiro: Rocco, 2011.

CUNHA, Murilo Bastos da. Para saber mais: fontes de informação em ciência e tecnologia. Brasília, DF: Briquet de Lemos/ Livros, 2001.

CUNHA, Murilo Bastos da; CAVALCANTI, Cordélia Robalinho de Oliveira. Dicionário de biblioteconomia e arquivologia. Brasília, DF: Briquet de Lemos/Livros, 2008.

DEL PRIORE, Mary Del. Biografia: quando o indivíduo encontra a história. Topoi, Rio de Janeiro, v. 10, n. 19, p. 7-16, jul./dez. 2009. Disponível em: 
http://www.scielo.br/pdf/topoi/v10n19/2237-101X-topoi-10-19-00007.pdf. Acesso em: 13 abr. 2020.

DOSSE, François. O desafio biográfico: Escrever uma vida. Tradução Gilson César Cardoso de Souza. São Paulo: Editora da Universidade de São Paulo, 2009.

GOMES, Marcos Aurélio; DUMONT, Lígia Maria Moreira. Possíveis relações entre o uso de fontes de informação e a competência em informação. Transinformação, Campinas, v. 27, n. 2, p. 133-143, maio/ago. 2015. Disponível em: http://www.scielo.br/scielo. php?pid=S010337862015000200133\&script=sci_abstract\&tlng=pt. Acesso em: 13 abr. 2020.

GROGAN, Denis. Science and technology: an introduction to the literature. London: Clive Bingley, 1970.

LE COADIC, Yves-François. A ciência de informação. Brasília: Briquet de Lemos, 1996.

LE GOFF, Jacques. História e Memória. Tradução Bernardo Leitão et al, Campinas, SP: Editora da UNICAMP, 1990.

LIMA, Maria Elenice Costa; MORAES, Vera Lúcia Albuquerque de. O enigma da escritura: Clarice Lispector mestre ou refém de sua escrita? Pontos de interrogação, Alagoinhas, v. 2, n. 1, p. 191-202, jan./jun. 2012. Disponível em: https://www.revistas.uneb.br/index.php/pontosdeint/article/view/1540/1002. Acesso em: 14 abr. 2020.

MOISÉS, Massaud. Análise literária. 17. Reimp. São Paulo: Cultrix, 1989.

MORIGI, Valdir José; BONOTTO, Martha Eddy K. King. A narrativa musical, memória e fonte de informação afetiva. Em Questão, Porto Alegre, v. 10, n. 1, p. 143-161, jan./jun. 2004. Disponível em: https://www.brapci.inf.br/index.php/res/v/11414. Acesso em: 28 abr. 2020.

MOTTA, Marly Silva da. O relato biográfico como fonte para a história. Vidya, Santa Maria, RS, n. 34, p. 101-122, jul./dez. 2000. Disponível em:

http://bibliotecadigital.fgv.br/dspace/handle/10438/6727?show=full. Acesso em: 13 abr. 2020.

OLIVEIRA, Ely Francina T. de; FERREIRA, Karen Eloise. Fontes de Informação online em arquivologia: uma avaliação métrica. Biblos, Rio Grande, v. 23, n. 2, p. 69-76. 2009.

Disponível em:

https://periodicos.furg.br/biblos/search/authors/view?firstName=Ely\&middleName=Francina \%20T.\%20de\&lastName=Oliveira\&affiliation=\&country=. Acesso em: 14 abr. 2020.

ROMANI, Carlo. Uma reflexão sobre biografia e subjetividade na História. Fênix: Revista de História e Estudos Culturais, v. 13, ano XIII, n. 1, jan./jun. 2016. Disponível em: http://www.revistafenix.pro.br/PDF37/artigo_18_secao_livre_Carlo_Romani_fenix_jan_jun_ 2016.pdf. Acesso em: 13 abr. 2020.

SÁ, Olga de. A escritura de Clarice Lispector. Petrópolis: Vozes; Lorena: Faculdades Integradas Teresa D'Ávila, 1979. 
SCHMIDT, Benito Bisso. Biografia e regimes de historicidade. MÊTIS: história \& cultura, v. 2, n. 3, p. 57-72, jan./jun. 2003. Disponível em: http://www.ucs.br/etc/revistas/index. php/metis/article/view/1041/707. Acesso em: 13 abr. 2020.

SILVA, Wilton Carlos Lima da. Biografias: Construção e reconstrução da memória. Fronteiras, Dourados, MS, v. 11, n. 20, p. 151-166, jul./dez. 2009. Disponível em: http://ojs.ufgd.edu.br/index. php/FRONTEIRAS/issue/archive. Acesso em: 13 abr. 2020.

SOLANO, Alexandre. Francisco. A biografia desafiada: os contornos de uma vida por François Dosse. Fênix: Revista de História e Estudos Culturais, v. 7, ano VII, n. 02, p. 1-10. 2010. Disponível em: http://www.revistafenix.pro.br/. Acesso em: 13 abr. 2020.

VIANNA, Márcia Milton; MARQUES JÙNIOR, Alaôr Messias. Fontes biográficas. In: CAMPELLO, Bernadete Santos; CALDEIRA, Paulo da Terra. (org.). Introdução às fontes de informação. 2. ed. Belo Horizonte: Autêntica Editora, 2008.

ZINANI, Cecil Jeanine Albert. O aspecto social da ficção de Clarice Lispector: uma perspectiva de abordagem. Antares, v. 9, n. 18, p. 22-33, jul./dez. 2017. Disponível em: http://www.ucs.br/etc/revistas/index. php/Antares/article/view/5892/3135.Acesso em: 14 abr. 2020. 